\title{
COMPÓSITOS POLIMÉRICOS PERMEÁVEIS COM RESÍDUOS DE CONSTRUÇÃO E DEMOLIÇÃO *
}

\author{
Rosana Vilarim da Silva ${ }^{1}$ \\ Nicholas Henrique dos Santos Rupp ${ }^{2}$ \\ Écio Bosi Junior ${ }^{3}$ \\ Victor de Brito Oliveira ${ }^{4}$ \\ Thiago de Almeida ${ }^{5}$ \\ Geórgia Serafim Araújo ${ }^{6}$ \\ André Itman Filho \\ Desílvia Machado Louzada ${ }^{8}$
}

Resumo

O objetivo deste trabalho foi desenvolver um compósito permeável formado por uma matriz de polipropileno reforçada com resíduos de construção e demolição (RCD). Inicialmente foi feita a limpeza, peneiramento e caracterização do RCD. O compósito foi conformado na forma de placas pelo processo de compressão a quente. O RCD foi misturado com os grânulos do polímero e a mistura disposta em um molde que foi fechado e comprimido com carga de 1 ton e mantido na temperatura de $210^{\circ} \mathrm{C}$ por 10 min. Foram conformadas placas permeáveis e impermeáveis variando-se o percentual dos constituintes e granulometria do RCD. Para a caracterização foram realizados ensaios de permeabilidade e flexão em três pontos. As placas permeáveis apresentaram elevado grau de permeabilidade, muito superior aos requisitos mínimos para concreto. Foi constatado que a distribuição granulométrica tem influência na resistência mecânica e permeabilidade do compósito. O aumento do teor de granulados finos promoveu aumento nas propriedades mecânicas em flexão sem perda da permeabilidade. Com a impermeabilização das placas e consequente redução de vazios as propriedades mecânicas em flexão praticamente triplicaram. Analisando os resultados de uma forma geral pode-se concluir que há margem para melhorar o desempenho mecânico do compósito sem perda da permeabilidade.

Palavras-chave: Resíduos de construção e demolição; Compósitos poliméricos; Permeabilidade.

\section{PERMEABLE POLYMERIC COMPOSITES WITH CONSTRUCTION AND DEMOLITION WASTE}

\begin{abstract}
The purpose of this work was to develop a permeable composite formed by a polypropylene matrix reinforced with construction and demolition waste (CDW). Initially the CDW was cleaned, sieving and characterized. The composite was molded as plates by hot pressing process. The CDW was mixed with the pellets of the polymer and disposed into the mold which was closed and compressed with 1 ton load and maintained at $210^{\circ} \mathrm{C}$ for $10 \mathrm{~min}$. Permeable and impermeable plates were formed by varying the constituents percentage and granulometry of the CDW. For characterization, permeability and three point bend tests were performed. The permeable plates presented high permeability degree, much higher than the minimum requirements for concrete. The change in the granulometric distribution of the RCD promoted increase in the mechanical properties without loss of permeability. The flexural properties of the impermeable plates were three times higher than that of the permeable plates. This occurred due to the voids reduction with the increase of the polymer percentage. By analyzing the results in a general way we can conclude that the composites mechanical properties can be improved without affecting the permeability.
\end{abstract}

Keywords: Construction and demolition waste; Polymeric composites; Permeability. 
1 Doutora em Ciência e Engenharia de Materiais pela Universidade de São Paulo - São Carlos, professora do Instituto Federal do Espirito Santo - IFES, Vitória-ES, Brasil.

2 Graduando em Engenharia Metalúrgica no Instituto Federal do Espírito Santo - IFES, Vitória-ES, Brasil.

3 Graduando em Engenharia Metalúrgica no Instituto Federal do Espírito Santo - IFES, Vitória-ES, Brasil.

4 Graduando em Engenharia Metalúrgica no Instituto Federal do Espírito Santo - IFES, Vitória-ES, Brasil.

5 Graduando em Engenharia Civil na Universidade Federal do Espírito Santo - UFES, Vitória-ES, Brasil.

6 Doutora em Engenharia Civil pela Universidad Politecnica de Cataluna, UPCATALUNA, Espanha, professora do Instituto Federal do Espirito Santo - IFES, Vitória-ES, Brasil.

7 Doutor em Engenharia e Ciência dos Materiais pela Universidade Federal de São Carlos - Ufscar, professor do Instituto Federal do Espirito Santo - IFES, Vitória-ES, Brasil.

8 Doutora em Engenharia Civil pela Universidad Politecnica de Cataluna, UPCATALUNA, Espanha, professora do Instituto Federal do Espirito Santo - IFES, Vitória-ES, Brasil. 


\section{INTRODUÇÃO}

O setor da construção civil gera um grande volume de resíduos e consome grande quantidade de matéria-prima natural. Entretanto muitos destes resíduos possuem um grande potencial de reaproveitamento no próprio setor, levando a uma redução da necessidade do uso de recursos naturais [1].

Dentre os materiais que podem ser reaproveitados na construção civil destacam-se os resíduos da construção e demolição (RCD). Estes são definidos pela Associação Brasileira para Reciclagem de Resíduos da Construção Civil e Demolição (ABRECON) como o conjunto de fragmentos ou restos de tijolo, concreto, argamassa, aço, madeira, etc; provenientes do desperdício na construção, reforma e/ou demolição de estruturas, como prédios, residências e pontes [2]. Atualmente grande número de empresas instituem sistemas de gerenciamento nos canteiros de obras e destinam esse tipo de resíduo às empresas especializadas na triagem e reciclagem de entulho. A reciclagem consiste basicamente na trituração e britagem do resíduo e classificação em faixas granulométricas.

Os principais usos do RCD são em pavimentação e como agregados para argamassas e concretos [1]. Ossa et al. [3] estudaram a aplicação do RCD como agregados em asfaltos para pavimentação urbana. Já Rahman et al. [4] estudaram a aplicação de diferentes tipos de RCD em materiais para pavimentação permeável, com capacidade de filtrar os poluentes que contaminam a água da chuva em áreas urbanas.

A utilização dos pavimentos permeáveis pode influenciar consideravelmente nas vazões de pico que ocorrem durante os eventos de chuva em determinado local [5]. Os pavimentos permeáveis asseguram, pela porosidade dos materiais, a retenção temporária da água, seguida pela drenagem e, se possível, a infiltração da mesma no solo [6]. O pavimento permeável proporciona ainda vantagens como ganhos ambientais, com a possibilidade de recarga de reservas subterrâneas, redução do escoamento superficial em relação às superfícies impermeáveis e benefícios financeiros associados à redução das dimensões do sistema de drenagem de jusante. Das áreas urbanas impermeabilizadas, as que teriam o maior potencial para se tornarem mecanismos de infiltração são as áreas de pavimentos, sejam elas vias de baixo tráfego, calçadas, pátios e estacionamentos [7].

Outro grande problema da indústria da construção civil é o grande consumo de cimento. O cimento é utilizado como principal aglomerante dos materiais de construção e sua fabricação é, sabidamente, uma atividade altamente impactante, seja pelo consumo de energia ou pela emissão de $\mathrm{CO}_{2}[8,9]$.

É neste cenário que se insere a proposta deste trabalho. Busca-se desenvolver um material de construção de baixo custo com grande potencial de aplicação em pavimentos permeáveis. Sendo assim foi desenvolvido um material compósito na forma de placas no qual os resíduos granulares (RCD) foram impregnados por um polímero que atua como ligante substituindo o cimento. O polímero utilizado foi 0 polipropileno (PP), um polímero termoplástico com alto potencial de reciclagem.

Além de produzir um material de menor custo que os materiais tradicionais utilizados na construção civil, a proposta pretende contribuir com o reaproveitamento desses resíduos e consequente minimização dos impactos ambientais gerados pelo seu descarte inadequado. 


\section{MATERIAIS E MÉTODOS}

\subsection{Materiais}

Para a confecção das placas de material compósito foi utilizado o polipropileno H301 na forma de grãos (pellets), fornecido pela Braskem e o RCD granulado, doado pela empresa Ureserra localizada em Serra-ES. A Tabela 1 apresenta as propriedades do polipropileno utilizado e a Figura 1 o RCD como recebido e os grânulos de PP.

Tabela 1. Características do polipropileno (PP) utilizado [10]

\begin{tabular}{lccc}
\hline \multicolumn{1}{c}{ Propriedades } & Método ASTM & Unidade & Valor \\
\hline Densidade & D 792 & $\mathrm{g} / \mathrm{cm}^{3}$ & 0,905 \\
\hline Módulo de flexão, secante a 1\% & D 790 & $\mathrm{MPa}$ & 1350 \\
\hline Resistência à tração no escoamento & D 638 & $\mathrm{Mpa}$ & 34 \\
\hline Alongamento no escoamento & D 638 & $\%$ & 11 \\
\hline Dureza Rockwell (Escala R) & D 785 & - & 98 \\
\hline Resistência ao impacto Izod a $23^{\circ} \mathrm{C}$ & D 256 & $\mathrm{~J} / \mathrm{m}$ & 25 \\
\hline Temperatura de deflexão térmica $(0,455 \mathrm{MPa})$ & D 648 & ${ }^{\circ} \mathrm{C}$ & 103 \\
\hline Temperatura de deflexão térmica $(1,820 \mathrm{MPa})$ & D 648 & ${ }^{\circ} \mathrm{C}$ & 53 \\
\hline Temperatura de amolecimento Vicat $(10 \mathrm{~N})$ & D 1525 & ${ }^{\circ} \mathrm{C}$ & 153 \\
\hline
\end{tabular}
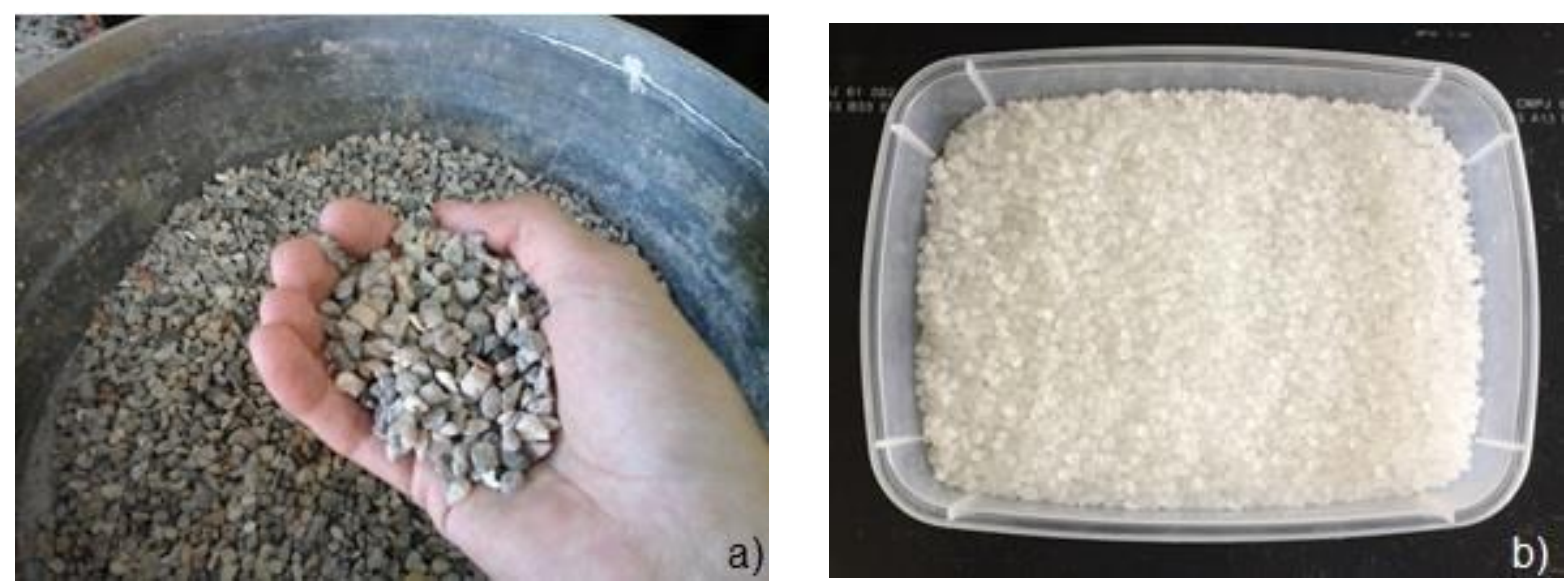

Figura 1. a) RCD granulado como recebido e b) grânulo de polipropileno (PP).

\subsection{Métodos}

\subsubsection{Preparação e Caracterização do RCD}

$\mathrm{O} R C D$, nas condições às quais foi obtido, foi peneirado em peneiras vibratórias e separado em 3 faixas granulométricas, conforme a Tabela 2.

Tabela 2. Faixas granulométricas do RCD

\begin{tabular}{cc}
\hline Faixa & Granulometria \\
\hline 1 & Menor que $9,5 \mathrm{~mm}$ e maior que $6,3 \mathrm{~mm}$ \\
\hline 2 & Menor que $6,3 \mathrm{~mm}$ e maior que $4,8 \mathrm{~mm}$ \\
\hline 3 & Menor que $4,8 \mathrm{~mm}$ e maior que $2,4 \mathrm{~mm}$ \\
\hline
\end{tabular}

O material retido na peneira de $9,5 \mathrm{~mm}$ e passante na peneira de $2,4 \mathrm{~mm}$ foi descartado para os fins de uso neste trabalho. Posteriormente o material foi lavado e impurezas como folhas, pregos e pós foram excluídas. O material foi espalhado 
sobre lonas plásticas em ambiente seco e refrigerado e deixado a secar por uma semana.

Para a identificação dos materiais presentes no RCD, e seus respectivos percentuais, foi feito um quarteamento para cada faixa granulométrica seguindo a norma NBR NM 27 [11]. Após a obtenção das amostras, as mesmas foram pesadas, seus componentes foram classificados e separados e em seguida pesados individualmente.

\subsubsection{Moldagem das Placas de Material Compósito}

Para a moldagem das placas foi utilizada uma termo-prensa com molde adaptado, apresentada na Figura 2. O molde é do tipo macho e fêmea e possui $240 \mathrm{~mm}$ de largura, $250 \mathrm{~mm}$ de comprimento e espessura variável de $3,2 \mathrm{~mm}$ a $20 \mathrm{~mm}$.

A primeira etapa de moldagem consiste da forragem do molde (macho) com um filme de poliimida que serve como desmoldante. Em seguida os grãos de PP e RCD, previamente pesados, são misturados e distribuídos manualmente dentro do molde; parte do PP é separado para ser distribuído sobre a superfície, no centro e nas laterais do molde. Um segundo filme desmoldante é posicionado sobre o material e o molde (fêmea) é fechado. O material foi submetido a uma carga de aproximadamente uma tonelada e aquecido até $210^{\circ} \mathrm{C}$, sendo mantido nesta temperatura por aproximadamente 10 minutos. Em seguida o material foi deixado a esfriar lentamente com o molde ainda fechado. A desmoldagem da placa foi realizada após o molde atingir a temperatura ambiente. Foram confeccionadas três tipos de placas de material compósito, duas permeáveis ( $P 1$ e $P 2)$ e uma impermeável que foi denominada de placa padrão e servirá de base para comparação. A Tabela 3 apresenta as características e composição das placas produzidas.
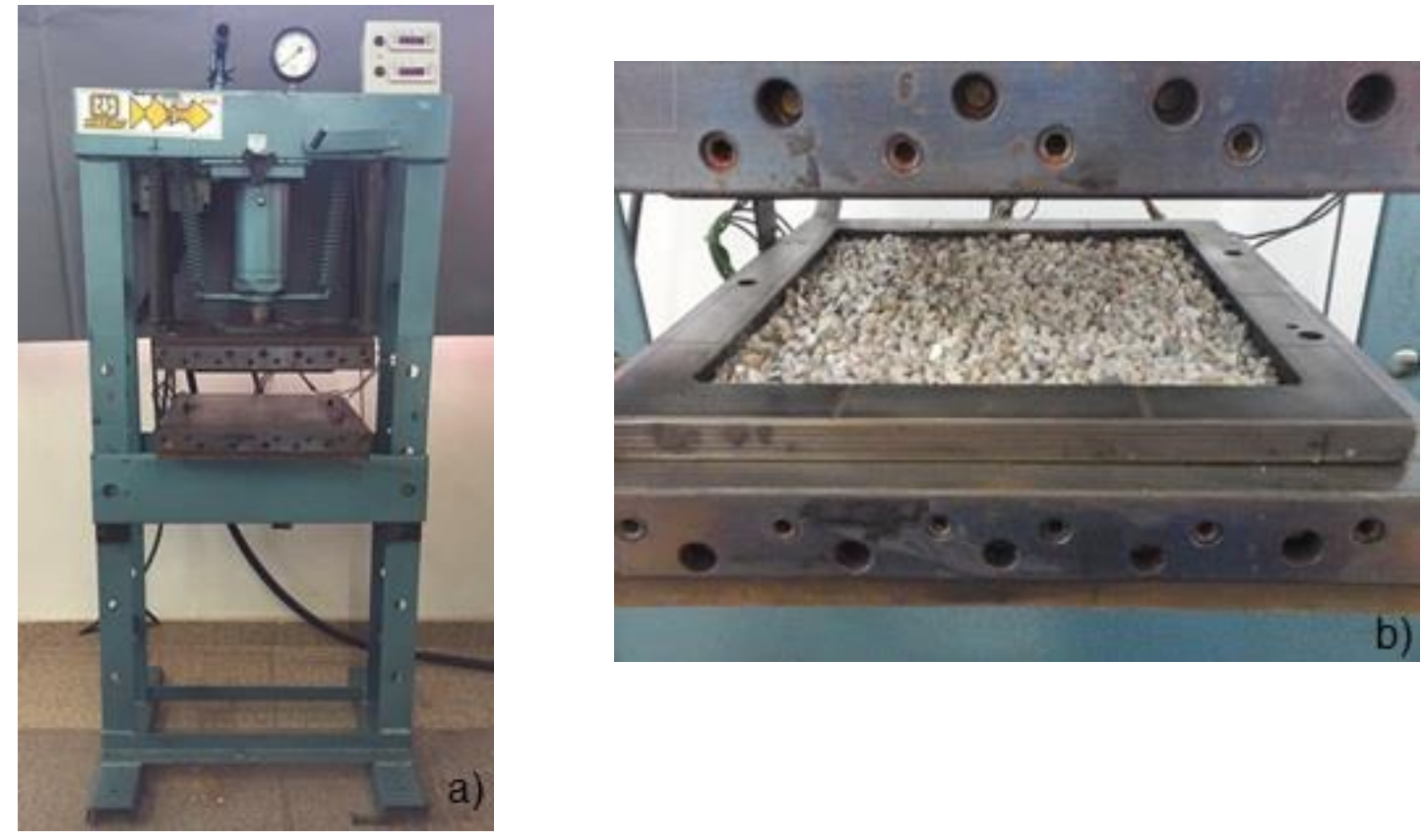

Figura 2. (a) Prensa térmica com molde adaptado e (b) Detalhe do molde com distribuição da mistura de RCD e PP. 
Tabela 3. Características das placas confeccionadas

\begin{tabular}{ccccccccc}
\hline Placas & $\begin{array}{c}\text { Número de } \\
\text { Placas } \\
\text { Produzidas }\end{array}$ & $\begin{array}{c}\text { \% em } \\
\text { massa } \\
\text { de PP }\end{array}$ & $\begin{array}{c}\text { \% em } \\
\text { massa } \\
\text { de RCD }\end{array}$ & $\begin{array}{c}\text { Massa } \\
\text { Total }(\mathbf{g})\end{array}$ & $\begin{array}{c}\text { Espessura } \\
\mathbf{( m m )}\end{array}$ & \multicolumn{2}{c}{$\begin{array}{c}\text { Granulometria do RCD } \\
\text { (\% em massa) }\end{array}$} \\
\cline { 8 - 10 } P1 & 5 & 18,3 & 81,7 & 930,0 & 13,39 & $10 \%$ & $70 \%$ & $20 \%$ \\
\hline P2 & 5 & 19,9 & 80,1 & 1356,6 & 19,26 & $10 \%$ & $60 \%$ & $30 \%$ \\
\hline$P_{\text {Padrão }}$ & 3 & 28,4 & 71,6 & 1516,6 & 19,93 & $10 \%$ & $60 \%$ & $30 \%$ \\
\hline
\end{tabular}

\subsubsection{Ensaio de Permeabilidade}

O procedimento para esse ensaio foi adaptado de Marchioni et al. [12], que utilizou a norma $\mathrm{ACl}-552 \mathrm{R}-06$, proposta pela American Concrete Institute para medir a permeabilidade de concreto. O permeâmetro utilizado foi construído especificamente para este trabalho e permite medir a permeabilidade da placa inteira sem a necessidade de retirada de amostras.

O permeâmetro, mostrado na Figura 3, consiste em duas caixas de acrílico que se encaixam perfeitamente. A placa a ser ensaiada é posicionada exatamente no encaixe das duas caixas. A caixa inferior possui um furo circular em uma das laterais, ao qual é acoplado um tubo de PVC de $100 \mathrm{~mm}$, conectado a um joelho, que é conectado a outro tubo, disposto para cima. A saída deste segundo tubo deve estar nivelada à superfície superior da placa. A caixa superior é aberta e possui duas marcações, uma a $7 \mathrm{~cm}$ acima do nível da placa e outra a $29 \mathrm{~cm}$. Após o encaixe da placa o sistema deve ser devidamente vedado, inclusive os contatos laterais entre a placa e as laterais da caixa de acrílico.

O ensaio é realizado fechando a saída do tubo de PVC e preenchendo-se todo o sistema com água. Em seguida a saída do tubo é aberta e o tempo que o nível de água leva para ir da marca de $29 \mathrm{~cm}$ até a de $7 \mathrm{~cm}$ é medido.

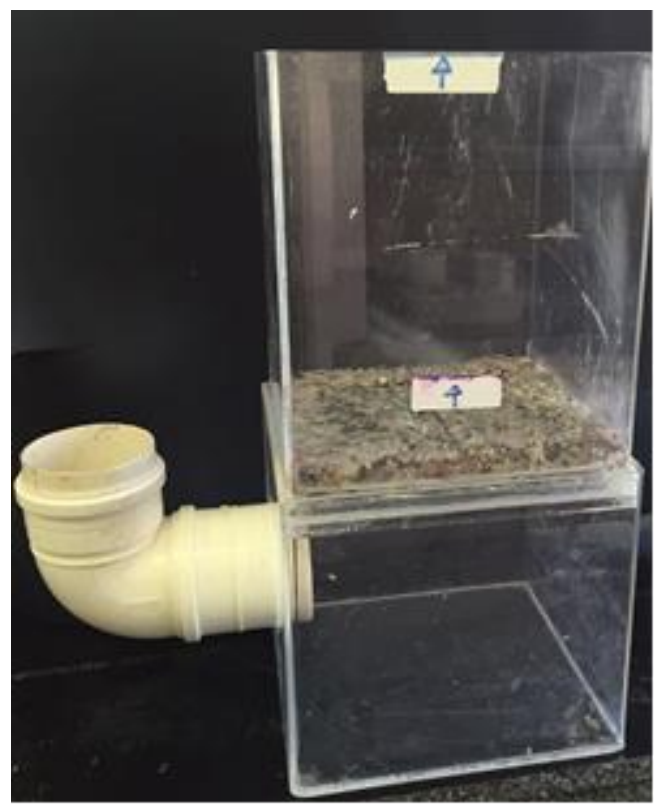

Figura 3. Permeâmetro construído especificamente para este trabalho.

A permeabilidade foi calculada segundo a Lei de Darcy (Equação 1):

$$
K=\frac{A_{1} L}{A_{2} t} \log \frac{h_{i}}{h_{f}}(1)
$$


Onde $\mathrm{K}$ é o coeficiente de permeabilidade em $\mathrm{cm} / \mathrm{s}, \mathrm{A}_{1}$ é a área de seção da amostra em $\mathrm{cm}, \mathrm{A}_{2}$ é a área do tubo em $\mathrm{cm}$, $\mathrm{L}$ é a espessura da amostra em $\mathrm{cm}, \mathrm{h}_{\mathrm{i}}$ é a altura inicial do nível d'água $(29 \mathrm{~cm}), h_{f}$ é a altura final $(7 \mathrm{~cm})$ e t é o tempo que o nível de água leva para ir de $h_{i}$ até $h_{f}$ em segundos. O teste foi repetido três vezes para cada placa. O resultado final consiste na média para cada grupo de placas.

\subsubsection{Ensaio de Flexão}

Os ensaios de flexão foram realizados em uma máquina universal de ensaios EMIC DL10000. Como não há normas específicas para este material, devido o seu caráter inovador, foram utilizadas as normas ABNT NBR 13818 [13], que trata da especificação e métodos de ensaios para placas de revestimento cerâmico, e a norma ASTM D 790-02 [14] que regulamente o ensaio de flexão para materiais poliméricos e seus compósitos. A Figura 4 mostra uma placa sendo ensaiada. Os apoios e o cutelo para este ensaio foram confeccionados especialmente para este trabalho de modo que a placa é ensaiada inteira sem a necessidade de confecção de corpos de prova. A distância entre os apoios foi de $220 \mathrm{~mm}$ e a velocidade de ensaio $2,5 \mathrm{~mm} / \mathrm{min}$. Foram utilizadas células de carga de $100 \mathrm{KgF}$ e de $10.000 \mathrm{KgF}$ a depender do tipo de placa ensaiada.

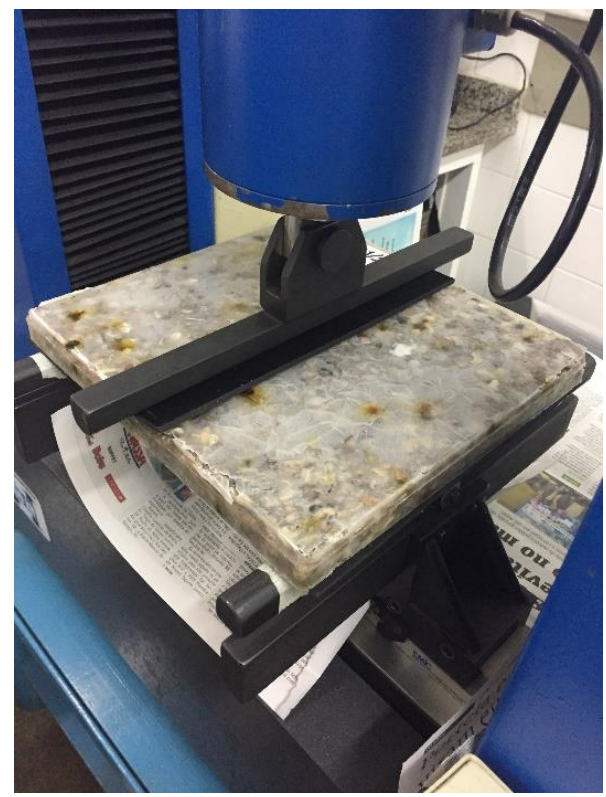

Figura 4. Placa posicionada para o ensaio de flexão.

Neste ensaio foram determinadas a carga de ruptura $(\mathrm{CR})$ e o módulo de resistência à flexão (MRF), calculados pelas Equações 2 e 3, respectivamente:

$$
\begin{array}{r}
C R=\frac{F \times L}{b} \\
M R F=\frac{3}{2} \times \frac{F \times L}{b \times e^{2}}
\end{array}
$$

Onde $F$ é a força de ruptura em newtons, $L$ é a distância entre os apoios em $\mathrm{mm}$, b é a largura da placa ao longo da ruptura em $\mathrm{mm}$ e "e" é a espessura média da placa em $\mathrm{mm}$. 


\section{RESULTADOS E DISCUSSÃO}

\subsection{Caracterização do RCD}

Os materiais que compõem o RCD foram identificados como: rochas naturais, argamassa de concreto, cerâmicas, gesso, pó e outros. A Figura 5 mostra os materiais identificados nas amostras analisadas, nas suas devidas proporções, e a Tabela 4 apresenta o percentual em massa de cada material para cada uma das 3 faixas granulométricas.

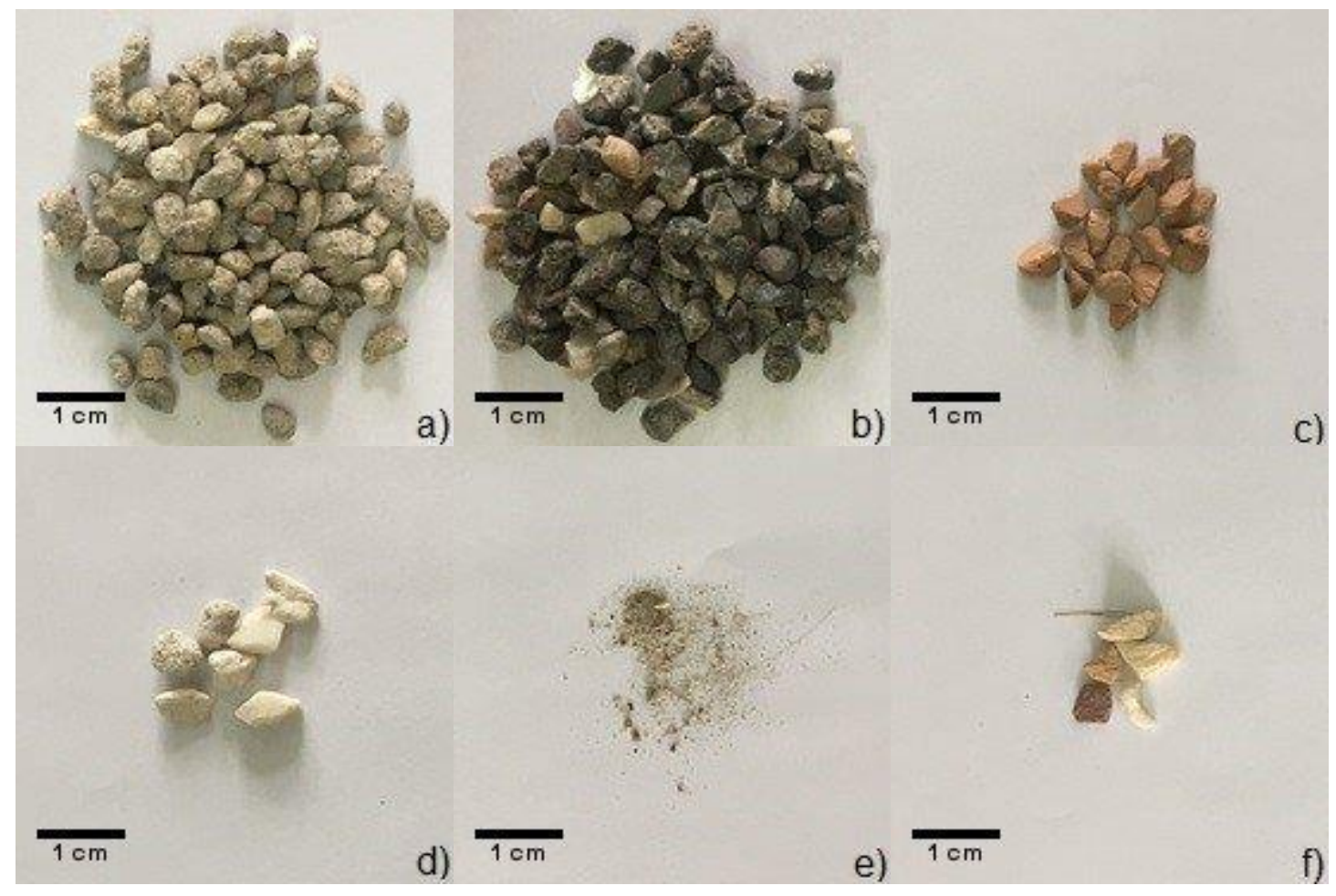

Figura 5. Materiais que compõem o RCD (faixa 2). a) Argamassa de concreto, b) Rochas naturais, c) Cerâmicos, d) Gesso, e) Pó e f) Outros.

Tabela 4. Composição do RCD para cada faixa granulométrica (percentual em massa)

\begin{tabular}{lccc}
\hline Faixa Granulométrica & Faixa 1 & Faixa 2 & Faixa 3 \\
\hline Argamassa de concreto & $48,59 \%$ & $48,22 \%$ & $47,46 \%$ \\
\hline Rochas naturais & $46,46 \%$ & $48,11 \%$ & $46,87 \%$ \\
\hline Cerâmicos & $2,25 \%$ & $1,05 \%$ & $1,19 \%$ \\
\hline Gesso & $0,31 \%$ & $0,81 \%$ & $1,02 \%$ \\
\hline Pó & $0,63 \%$ & $0,97 \%$ & $1,14 \%$ \\
\hline Outros & $1,74 \%$ & $0,83 \%$ & $2,31 \%$ \\
\hline
\end{tabular}

A composição para as diferentes faixas granulométricas é semelhante, conforme observado na Tabela 4. Os materiais que se apresentam em maior quantidade são as rochas naturais e a argamassa de concreto, sendo ambos os materiais de maior resistência dentre os que compõem o RCD e, portanto, os mais desejáveis. Materiais como gesso e pós são os mais indesejáveis; o gesso possui baixa resistência mecânica e os pós preenchem os vazios do compósito reduzindo a permeabilidade do mesmo. Entretanto, como estão em pequeno percentual acredita-se que tenham pouca influência no desempenho do material. 


\subsection{Processo de Moldagem das Placas}

Na Figura 6 são apresentadas duas placas do compósito desenvolvido, uma permeável e uma impermeável. A Figura 7 apresenta a seção transversal das placas na região de fratura após o ensaio de flexão. A placa permeável (Figura 6a) apresentou espessura e superfície irregulares sendo possível visualizar boa parte dos agregados, já que o polímero não recobre completamente a placa. Intencionalmente há predominância de polímero nas bordas da placa para garantir boa estabilidade. Na Figura 7a são observados vários vazios e agregados com molhabilidade incompleta. A superfície inferior (base) da placa é mais uniforme que a superior.

Já as placas impermeáveis (Figura 6b), apresentaram superfícies regulares, completamente recobertas pelo polímero garantindo a impermeabilidade. Pontos escuros na superfície indicam início de degradação do polímero. $\mathrm{Na}$ seção transversal da placa (Figura 7b) nota-se que os agregados estão completamente recobertos por polímero e que não há descolamento dos mesmos indicando boa adesão. Há excesso de polímero na superfície superior da placa e vazios subsuperficiais.

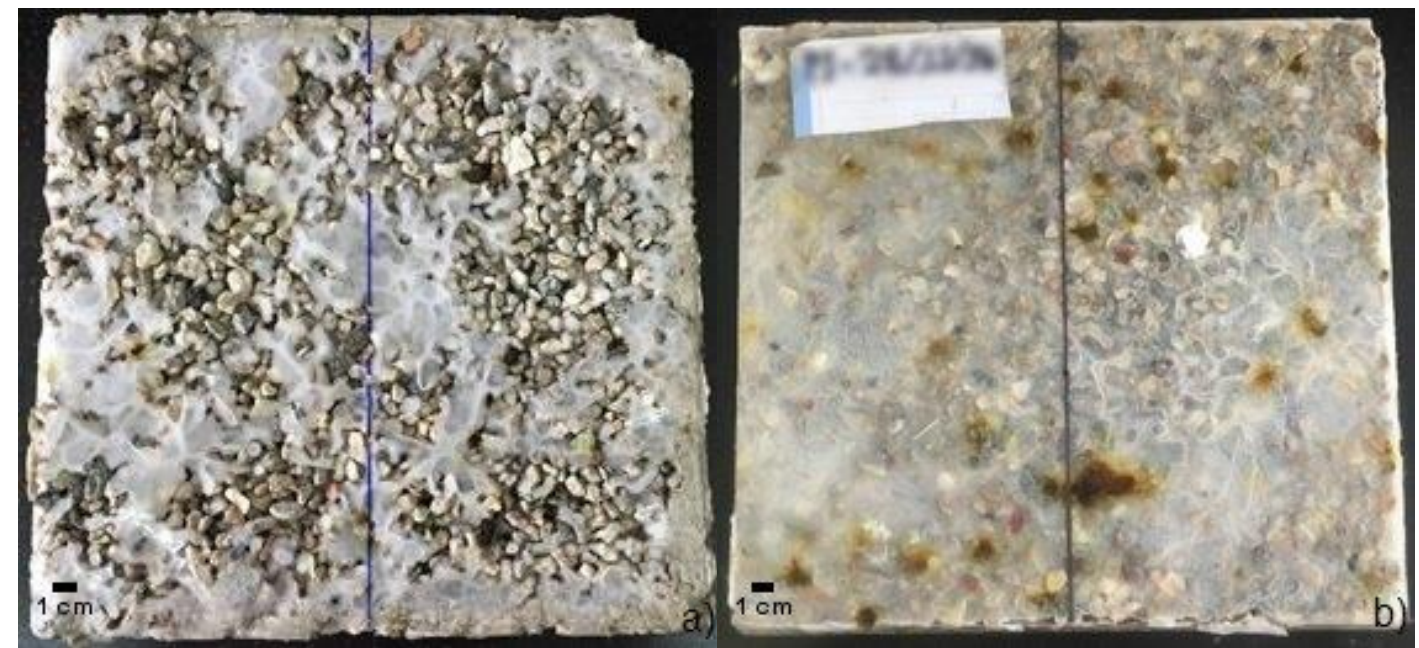

Figura 6. Superfície superior das placas. a) Placa permeável (P2), b) Placa impermeável (P Padrão).
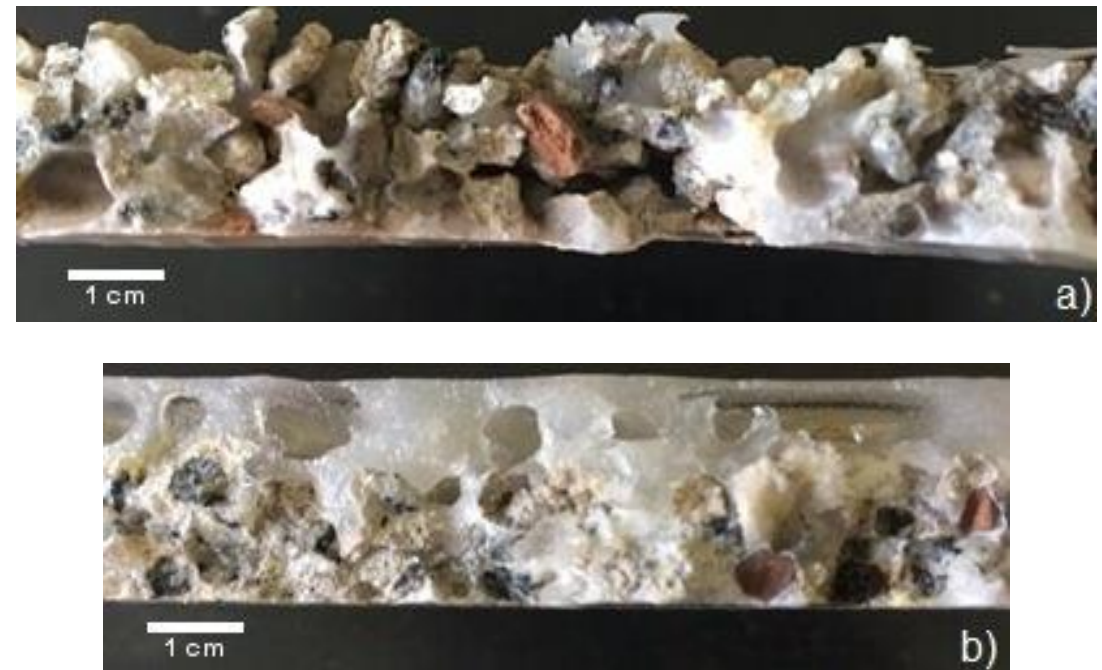

Figura 7. Seção transversal de placas fraturadas em flexão. a) Placa permeável (P2), b) Placa impermeável (P Padrão). 


\subsection{Ensaio de Permeabilidade}

Os ensaios de permeabilidade foram realizados, obviamente, apenas para as placas permeáveis (P1 e P2). Os valores dos coeficientes de permeabilidade obtidos são apresentados na Tabela 5. A norma ACl-552R- 6 considera que para o material ser considerado permeável o coeficiente de permeabilidade (K) deve maior que 0,001 $\mathrm{cm} / \mathrm{s}$.

Tabela 5. Coeficientes de Permeabilidade $(\mathrm{K}) \mathrm{em} \mathrm{cm} / \mathrm{s}$

\begin{tabular}{ccc}
\hline Placas & P1 & P2 \\
\hline $\mathrm{K}(\mathrm{cm} / \mathrm{s})$ & 0,747 & 0,307 \\
\hline
\end{tabular}

Observa-se que as placas P1 e P2 atendem perfeitamente aos requisitos da norma sendo, portanto, consideradas permeáveis. A diferença fundamental entre os dois tipos de placas é a granulometria, as placas do tipo P2 possuem um maior teor de granulados finos (ver Tabelas 2 e 3), o que tenderia a reduzir sua permeabilidade em relação às do tipo $\mathrm{P} 1$, por haver um menor volume de vazios no interior das mesmas. Isto realmente ocorreu, como pode ser observado na Tabela 5, as placas do tipo P2 têm menor permeabilidade, porém, a redução é pequena já que os valores de $\mathrm{K}$ se mantêm na mesma ordem de grandeza.

\subsection{Ensaio de Flexão}

Os resultados dos ensaios de flexão são apresentados na Tabela 6. Foram determinadas as seguintes propriedades: Carga de Ruptura (CR) e Módulo de Resistência à Flexão (MRF) conforme Equações 2 e 3. Foram também determinadas as propriedades específicas (propriedade/espessura) sendo estas denominadas de: Carga de Ruptura Específica $(\mathrm{CRe})$ e o Módulo de Resistência à Flexão Específico (MRFe).

Tabela 6. Resultados dos Ensaios de Flexão

\begin{tabular}{cccccc}
\hline Placas & CR (N) & MRF (Mpa) & CRe (N/cm) & $\begin{array}{c}\text { MRFe } \\
(\mathbf{M p a} / \mathbf{m m})\end{array}$ & $\begin{array}{c}\text { Espessura } \\
(\mathbf{m m})\end{array}$ \\
\hline P1 & 205,70 & 1,76 & 153,58 & 1,31 & 13,39 \\
\hline P2 & 826,83 & 3,34 & 429,30 & 1,73 & 19,26 \\
\hline P Padrão & 2331,39 & 8,84 & 1169,59 & 4,43 & 19,93 \\
\hline
\end{tabular}

Pode-se observar na Tabela 6 que as placas do tipo P2 apresentaram propriedades superiores às do tipo P1, tanto a Carga de Ruptura quanto o Módulo de Resistência à Flexão, como também suas correspondentes propriedades específicas. Além de uma maior espessura as placas P2 possuem diferença na granulometria, um maior percentual da faixa granulométrica mais fina (faixa 3) e menor percentual da faixa intermediária (faixa 2), em relação às placas P1 (ver Tabela 3). Analisando apenas as propriedades específicas, o que exclui a influência da espessura na análise, pode-se observar que a mudança na granulometria das placas promoveu aumento de aproximadamente $64 \%$ na CRe e $24 \%$ no MRFe. Esta melhoria ocorreu devido a maior parcela de granulados finos no material; o granulado fino ocupa os espaços disponíveis entre os granulados maiores reduzindo o número de vazios no compósito. Os vazios tendem a reduzir à resistência a flexão do compósito, pois atuam como concentradores de tensões e favorecem a formação de trincas. Entretanto, é importante lembrar que a permeabilidade é essencial para este 
material, portanto os vazios devem estar presentes em quantidade suficiente para garantir essa propriedade. Este foi o maior desafio deste trabalho, ajustar a granulometria de modo a obter boa permeabilidade sem grande prejuízo das propriedades mecânicas. Pode-se afirmar que a distribuição granulométrica utilizada em P2 foi mais eficiente do que a utilizada em P1.

Para determinar a resistência máxima que poderia ser obtida para este compósito foram confeccionas placas impermeáveis (denominadas de P Padrão) com o menor número de vazios possível. Estas placas possuem a mesma distribuição granulométrica das placas do tipo P2 e praticamente a mesma espessura. Comparando P Padrão com P2 nota-se que os valores de CR e MRF praticamente triplicaram. Isso ocorreu pois, ao se aumentar o percentual da matriz polimérica 0 número de vazios foi reduzido e a área de contado entre a matriz e o reforço aumentou, melhorando a transferência de carga da matriz para o reforço através da interface. Analisando de uma forma geral os resultados apresentados conclui-se que há margem para melhorar ainda mais o desempenho mecânico do compósito sem perder a característica de permeabilidade. O material mostra-se promissor para uso como pavimentos permeáveis em situações de baixo tráfego.

\section{CONCLUSÕES}

- Cerca de 95\% do RCD é composto por argamassa de concreto e rochas, materiais de boa resistência mecânica.

- O processo de moldagem das placas de compósito foi satisfatório apesar da irregularidade na espessura das mesmas, particularmente das placas permeáveis.

- As placas do compósito permeável apresentaram elevado grau de permeabilidade, da ordem de 100 vezes superior ao mínimo exigido pela norma $\mathrm{ACl}-552 \mathrm{R}-06$.

- A alteração na distribuição granulométrica do reforço, aumentando o percentual de finos e reduzindo o de grossos, promoveu aumento nas propriedades mecânicas em flexão das placas de compósito permeável sem perda da permeabilidade.

- Com a impermeabilização das placas e consequente redução de vazios as propriedades mecânicas em flexão praticamente triplicaram.

- Analisando os resultados de uma forma geral pode-se concluir que há margem para melhorar o desempenho mecânico do compósito sem prejuízo da permeabilidade.

\section{Agradecimentos}

Os autores agradecem ao Ifes pelo apoio para a realização da pesquisa e ao CNPq, FAPES e Ifes pelas bolsas de Iniciação Científica concedidas. Agradecem também a empresa Ureserra, localizada em Serra-ES, pela doação dos granulados reciclados. 


\section{REFERÊNCIAS}

1 Ângulo SC, Zordan SE, John VM. Desenvolvimento sustentável e a reciclagem de resíduos na construção civil. 2001 [acesso em 18 maio 2017]. Disponível em: http://www.casoi.com.br/hjr/pdfs/RDC.pdf.

2 Associação Brasileira para Reciclagem de Resíduos da Construção Civil e Demolição [página da internet]. São Paulo: ABRECON [acesso em 18 maio 2017]. Disponível em: http://www.abrecon.org.br/o-que-e-entulho/.

3 Ossa A, García JL, Botero E. Use of recycled construction and demolition waste (CDW) aggregates: A sustainable alternative for the pavement construction industry. Journal of Cleaner Production. 2016;135:379-386.

4 Rahman A, Imteaz MA, Arulrajah A, Piratheepan J, Disfani MM. Recycled construction and demolition materials in permeable pavement systems: geotechnical and hydraulic characteristics. Journal of Cleaner Production. 2015;90:183-194.

5 Batezini R. Estudo preliminar de concretos permeáveis como revestimento de pavimentos para áreas de veículos leves [dissertação de mestrado]. São Paulo: Universidade de São Paulo; 2013.

6 Acioli LA. Estudo experimental de pavimentos permeáveis para o controle do escoamento superficial na fonte [dissertação de mestrado]. Porto Alegre: Universidade Federal do Rio Grande do Sul; 2005.

7 Associação Brasileira de Cimento Portland [página da internet]. São Paulo: ABCP [acesso em 18 maio 2017]. Disponível em: http://www.abcp.org.br/cms/download/.

8 Cement Sustainability Initiative. Iniciativa para a sustentabilidade do cimento: Plano de ação. Genebra: CSI; 2002.

9 Cardoso BH, Canazaro CC, Mancio M. Durabilidade e sustentabilidade das estruturas: desafios e oportunidades. In: Resíduos Sólidos e Mudanças Climáticas. Anais do 7ํㅜ Fórum Internacional de Resíduos Sólidos; 2016; Porto Alegre, Brazil.

10 BRASKEM. Polipropileno H 301: Folha de dados. São Paulo: BRASKEM; 2012.

11 Associação Brasileira de Normas Técnicas. NBR NM 27: agregados - redução da amostra de campo para ensaios de laboratório. Rio de Janeiro: ABNT; 2001.

12 Marchioni ML, Silva CO, Mayor AV. Conceitos e requisitos para pavimentos de concreto permeável. Sistemas construtivos - Pavimentos Permeáveis, ABCP Associação Brasileira de Cimento Portland. São Paulo, 2011.

13 Associação Brasileira de Normas Técnicas. NBR 13818: placas cerâmicas para revestimento - especificação e métodos em ensaio. Rio de Janeiro: ABNT; 1997.

14 American Society for Testing and Materials. D790 - 02: standard test methods for flexural properties of unreinforced and reinforced plastics and electrical insulating material. Philadelphia: ASTM; 2002. 